\title{
The role of gonadotropin-releasing hormone agonists in female fertility preservation
}

\author{
Jae Hoon Lee ${ }^{1,2}$, Young Sik Choi ${ }^{2,3}$ \\ 'Department of Obstetrics and Gynecology, Gangnam Severance Hospital, Yonsei University College of Medicine, Seoul; ${ }^{2}$ Institute of Women's \\ Life Medical Science, Yonsei University College of Medicine, Seoul; ${ }^{3}$ Department of Obstetrics and Gynecology, Severance Hospital, Yonsei \\ University College of Medicine, Seoul, Korea
}

Advances in anticancer treatments have resulted in increasing survival rates among cancer patients. Accordingly, the quality of life after treatment, particularly the preservation of fertility, has gradually emerged as an essential consideration. Cryopreservation of embryos or unfertilized oocytes has been considered as the standard method of fertility preservation among young women facing gonadotoxic chemotherapy. Other methods, including ovarian suppression and ovarian tissue cryopreservation, have been considered experimental. Recent large-scale randomized controlled trials have demonstrated that temporary ovarian suppression using gonadotropin-releasing hormone agonists (Gn$\mathrm{RHa}$ ) during chemotherapy is beneficial for preventing chemotherapy-induced premature ovarian insufficiency in breast cancer patients. It should also be emphasized that GnRHa use during chemotherapy does not replace established fertility preservation methods. All young women facing gonadotoxic chemotherapy should be counseled about and offered various options for fertility preservation, including both GnRHa use and cryopreservation of embryos, oocytes, and/or ovarian tissue.

Keywords: Chemotherapy; Fertility preservation; Gonadotropin-releasing hormone agonist; Premature menopause

\section{Introduction}

Advances in anticancer treatments have resulted in increasing survival rates among cancer patients. In South Korea, the overall cancer mortality rate decreased by $2.7 \%$ annually between 2002 and 2016 . A significant improvement was also evident in the 5-year survival rate, which increased to $70.6 \%$ for patients diagnosed with cancer between 2012 and 2016, compared with 41.2\% for patients diagnosed between 1993 and 1995 [1]. Accordingly, the idea that quality of life after cancer should be actively considered during cancer treatment has become widely accepted. In particular, the preservation of

Received: August 26, 2020 • Revised: October 13, 2020 • Accepted: October 13, 2020 Corresponding author: Young Sik Choi

Department of Obstetrics and Gynecology, Severance Hospital, Yonsei University College of Medicine, 50-1 Yonsei-ro, Seodaemun-gu, Seoul 03722, Korea Tel: +82-2-2228-2230 Fax: +82-2-313-8357 E-mail:YSCHOI08@yuhs.ac *This study was supported by the Korea Health Technology R\&D Project through the Korea Health Industry Development Institute, funded by the Ministry of Health \&Welfare, Republic of Korea (HI18C2047).

This is an Open Access article distributed under the terms of the Creative Commons Attribution Non-Commercial License (http://creativecommons.org/licenses/by-nc/4.0/) which permits unrestricted non-commercial use, distribution, and reproduction in any medium, provided the original work is properly cited. fertility in younger patients receiving cancer treatment has gradually become an essential factor for consideration [2-4]. The main problems associated with chemotherapy in female cancer survivors include early menopause and an increased subfertility rate [5]. For fertility preservation in women, embryo and oocyte cryopreservation are considered to be the standard practice and are widely available [2-4]. However, because embryo and oocyte cryopreservation requires approximately 2 weeks, it is difficult to perform cryopreservation in patients with cancers for which treatment is more urgent due to rapid progression. In addition, cryopreservation may not be an option for all women for economic reasons.

There has been tremendous interest in medical agents that can potentially preserve fertility from the ovarian toxicity of chemotherapy, and gonadotropin-releasing hormone agonists $(\mathrm{GnRHa})$ have been considered to be the most likely category of drugs for this purpose. In 1981, an animal study demonstrated that GnRHa administration protected male mice from gonadal damage caused by cyclophosphamide [6]. An observational long-term follow-up study of children treated with chemotherapy for Hodgkin disease showed that prepubertal administration of chemotherapy agents resulted in 
less ovarian damage than in similarly treated adult patients, and it was suggested that GnRHa could exert a protective role by creating a temporary "prepubertal" state in women of reproductive age [7]. The first randomized controlled trial (RCT) of GnRHa for preserving fertility during chemotherapy was conducted by Waxman et al. [8] in 1987. The authors reported that buserelin was not effective in preserving fertility. Since this first RCT was reported, several other RCTs and observational studies have been conducted in patients with various diseases, including breast cancer, hematological malignancies, and autoimmune diseases. However, these studies have reported conflicting results [9].

Although the mechanisms of protection have yet to be fully understood, as the results of large-scale RCTs were recently released, researchers' understanding of the conditions under which $\mathrm{GnRHa}$ can preserve fertility has been expanded and clarified. This trend was reflected in the 2018 American Society of Clinical Oncology (ASCO) guidelines for fertility preservation [4]. The 2018 ASCO guidelines stated for the first time that GnRHa may partially help in preserving fertility in patients undergoing chemotherapy. These changes in the ASCO guidelines have also influenced other guidelines released after $2018[10,11]$. Nevertheless, evidence regarding the efficacy of $\mathrm{GnRHa}$ for fertility preservation is still regarded as insufficient, and $\mathrm{GnRHa}$ use during chemotherapy does not replace established fertility preservation methods. In this review, we describe the scope of utility and limitations of $\mathrm{GnRHa}$ in preserving fertility, as well as the mechanisms by which $\mathrm{GnRHa}$ protects the ovaries from chemotherapy.

\section{How do chemotherapeutic agents damage the ovary?}

Although controversial [12], it is generally believed that the number of follicles held within the primordial follicle (PMF) pool is finite. PMFs form from 17 weeks of gestation, and consist of an immature oocyte in meiotic arrest surrounded by a single layer of granulosa cells. During the reproductive age, both the oocyte and surrounding granulosa cells undergo stages of sequential growth and development, characterized by granulosa cell proliferation and oocyte growth, until resumption of meiosis by the ovulatory luteinizing hormone (LH) surge. PMFs are continuously being recruited out of the pool of germ cells and activated to grow until few remain. The presence of fewer than 1,000 remaining oocytes has been associated with menopause [13,14].

The risk of developing premature ovarian insufficiency (POI) after chemotherapy can vary depending on various factors. Some chemotherapy regimens are considered more gonadotoxic than others, with particularly strong evidence for the high toxicity of alkylating agents [14]. Dosage of the treatment used is also an important con- sideration, and previous studies have shown that early menopause occurs in a dose-dependent fashion [15]. In addition, the age of the patient at treatment is pivotal, as older women have a much higher reported incidence of $\mathrm{POI}$ during or immediately after treatment $[5,16]$. Chemotherapy undoubtedly has a detrimental effect directly on follicles [14], and previous studies have shown that chemotherapy acts on the ovary in a wide variety of ways (Table1).

\section{Burnout theory}

Chemotherapy-induced POI has been attributed to the loss of PMFs not only through the direct effects of chemotherapeutic agents, but also as a result of an increased rate of folliculogenesis to replace the damaged developing follicles. Meirow's group $[17,18]$ proposed the "burnout theory" in an attempt to describe enhanced follicular demise owing to accelerated folliculogenesis in the ovary after gonadotoxic chemotherapy. In animal studies, increased phosphorylation of proteins through the phosphatidylinositol 3-kinase signaling pathway, which stimulates accelerated PMF activation in both oocytes and granulosa cells, was observed after administration of alkylating agents, resulting in the burnout effect and marked loss of the PMF pool during repeated cycles of anticancer treatment. $[17,18]$ Furthermore, there is an extended version of the burnout theory explained by the reduced secretion of sex steroid hormones and the resulting mechanism of feedback. Gonadotoxic agents have been reported to induce acute loss of the growing follicle population, resulting in decreased secretion of sex steroid hormones and inhibin [19]. Low systemic concentrations of sex steroid hormones and inhibin then result in an inhibition of negative feedback on the pituitary gland and hypothalamus in order to increase gonadotropin secretion, mainly follicle-stimulating hormone (FSH). Increased FSH concentrations then enhance the rate of resting preantral follicle recruitment and maturation and the ability to enter the process of folliculogenesis. Due to the active metabolism of dividing cells during folliculogenesis, these growing follicles are subjected to the gonadotoxic effects of chemotherapy, resulting in an accelerated rate of follicular depletion $[19,20]$.

\section{Target of chemotherapy: germ cells or granulosa cells?}

It has often been assumed that chemotherapy acts directly on the oocyte within immature follicles, initiating the death of germ cells. However, studies have thus far reported that chemotherapy targets not only oocytes [21-24], but also granulosa cells [25-27], and even ovarian stromal cells and blood vessels [14,28-30]. Oocytes are held in meiotic arrest within immature follicles, although they rapidly grow in developing follicles. Because chemotherapeutic agents are designed to act upon dividing cells, whether mitotically active granulosa cells are the target of chemotherapy drugs remains a subject of 
research. Granulosa cells have been reported to surround the oocyte and proliferate during follicle maturation. Considering the bidirectional interaction between the oocyte and the granulosa cells, with each regulating the growth and maturation of the other [31], damage to granulosa cells may result in indirect damage to the oocyte, which in turn can lead to germ-cell loss [14]. A study of ovarian biopsies from 10 girls who underwent treatment for leukemia found moderate to severe signs of stromal fibrosis and capillary changes [29]. In another human study, injury to blood vessels and focal ovarian cortical fibrosis were reported after exposure to chemotherapy, suggesting that local ischemia may be a potential additional mechanism by which follicles are lost [28].

\section{Which stages of follicles are vulnerable to chemotherapy?}

Follicles within the ovary are at various stages of maturation. It is possible that specific stages are more susceptible to damage after chemotherapy than others. Because previous studies have mainly examined the effects of different anticancer drugs on PMFs, there are limited data on this question [14]. Cyclophosphamide and its metabolites have reportedly decreased the number of PMFs and small primary follicles in rodent ovaries [32,33]. In humans, ovarian biopsies from patients treated with chemotherapy had significantly lower PMF counts [34]. Nonetheless, several studies have reported that more mature follicles, as well as PMFs, are affected by anticancer drugs $[24,25,30,35]$. Preantral follicles have been shown to be susceptible to chemotherapy, with deterioration in follicle quality after chemotherapy in humans [35]. In conclusion, there is evidence that chemotherapy causes damage to follicles at all stages, from primordial to antral follicles [14]. However, no experiment has conducted a comparative analysis to determine which follicle stage is more susceptible to anticancer drugs.

\section{Different mechanisms of different chemotherapeutic agents}

Direct cellular effects on various components of the ovary have been determined for various classes of chemotherapies that differ in their specific cellular targets. Doxorubicin is an anthracycline often used to treat lymphomas, leukemia, breast cancer, and sarcomas. It has been hypothesized to intercalate with DNA and prevent its replication and transcription [22]. Doxorubicin may interfere with the electron transport chain, leading to a release of cytochrome c into the cytosol. This activates the caspase family of proteins, in turn causing apoptosis and even cell death. There is evidence that In the cell nucleus, doxorubicin upregulates the expression of p53, a DNA repair protein that initiates apoptosis in the presence of high levels of DNA damage [36]. Doxorubicin could then affect the ovary by all of these mechanisms, but it primarily affects mitotically and metabolically active cells, as well as granulosa cells, rather than oocytes [37].
Cyclophosphamide is an alkylating agent that results in intra- and inter-strand crosslinking of DNA, which reportedly interferes with cell division [14]. The effects of alkylating agents have been examined in the granulosa cells of rat ovaries. As with doxorubicin, cyclophosphamide has also shown a mitochondrial effect, as it induces a reduction in mitochondrial transmembrane potential and an accumulation of cytochrome $\mathrm{c}$ in the cytosol, again leading to the activation of the caspase family and apoptosis [27].

Cisplatin interacts with DNA to form DNA adducts, primarily intra-strand crosslink adducts, which can activate several signal transduction pathways, including those involving ATR, p53, p73, and MAPK, culminating in the activation of apoptosis [38]. Cisplatin administration to neonatal mouse ovaries has been identified to cause an accumulation of Abl, a nonreceptor tyrosine kinase, and TAp63-a, a homologue of $\mathrm{p} 53$, which is expressed in the oocyte, leading to oocyte death $[24,39]$

\section{Gonadotoxicity by high gonadotropin concentrations}

High gonadotropin concentrations after chemotherapy have also been suggested to affect the resting PMF pool. An in vivo study using mice that produced chronically elevated levels of serum LH via expression of an LH $\beta$-subunit transgene reported a significant premature loss of their primordial and primary follicle pool 3 months after birth. These transgenic mice had a similar number of follicles as wildtype controls at birth. The finding that chronically elevated LH levels depleted the PMF pool implies that chronic LH elevation might hasten the onset of reproductive senescence [40]. It is believed that PMFs and primary follicles are gonadotropin-independent. However, several investigations have suggested that these follicles express mRNA for FSH and LH receptors [40-49]. These studies have also provided support for the possibility that even immature follicles, such as the primordial and primary follicles, may be gonadotropin-dependent $[42-45,49,50]$. Moreover, in adult sheep ovaries, FSH was found to modulate ovarian germinative stem cells and their progenitors via $\mathrm{FSH}-\mathrm{R3}$, an isoform of the FSH receptor, to undergo potential self-renewal, clonal expansion, and differentiation into oocytes [49].

\section{Potential mechanisms through which $\mathrm{GnRHa}$ minimizes the ovarian toxicity of chemotherapy}

Although there is still controversy regarding the efficacy of $\mathrm{GnRHa}$ on ovarian protection, recent studies have been able to better clarify the efficacy of temporary ovarian suppression with GnRHa during chemotherapy, especially in breast cancer patients (Table 1).

\section{Simulating the prepubertal hormonal milieu}

The administration of $\mathrm{GnRHa}$ has been identified to induce an ini- 
tial release of gonadotropins, which desensitize the GnRH receptors on the pituitary gonadotropes, preventing pulsatile GnRH secretion, resulting in a hypogonadotropic, prepubertal hormonal milieu. It has been suggested that in this hypogonadotropic milieu, the follicles remain in the quiescent phase and are thus less vulnerable to chemotherapy-induced gonadotoxicity [51]. However, this mechanism is controversial because of the dogma that primordial and primary follicles are not gonadotropin-dependent. However, the growth of primordial and primary follicles is affected by many factors, such as the transforming growth factor superfamily, the bone morphogenetic proteins $(-4,-7$, and -9$)$, and activin, which is secreted by gonadotropin-dependent antral follicles in a paracrine way $[44,52,53]$. These growth factors may also induce the exit of PMFs from the dormant inactive pool [44]. The rate at which PMFs leave the non-active resting pool is influenced by the presence or absence of the more advanced gonadotropin-dependent growing follicles [14]. Moreover, as described above, a few studies support the possibility that even immature follicles such as the primordial and primary follicles may be gonadotropin-dependent $[42-45,49,50]$.

Therefore, GnRHa cotreatment, after the initial flare-up effect, decreases FSH levels through pituitary desensitization, preventing the secretion of growth factors by the more advanced FSH-dependent follicles, and secondarily preserves more PMFs in the dormant stage.

\section{Interrupting the burnout effect}

GnRHa may minimize POl by interrupting the burnout effect after gonadotoxic agents. Specifically, the administration of GnRHa may interfere with the accelerated follicle recruitment induced by chemotherapy by desensitizing the $\mathrm{GnRH}$ receptors in the pituitary gland, preventing an increase in FSH concentration despite low estrogen and inhibin levels $[14,41,54]$. However, there is no experimental support for this hypothesis; moreover, primordial and primary follicles are generally believed to be gonadotropin-independent, as mentioned above.

\section{Decreased utero-ovarian perfusion}

Another possible explanation for the beneficial effect of GnRHa cotreatment in reducing chemotherapy-associated gonadotoxicity is decreased utero-ovarian perfusion, which results from the hypoestrogenic milieu generated by pituitary-gonadal desensitization $[55,56]$. High estrogen levels increased ovarian perfusion in a rat model, and administration of GnRHa significantly inhibited this effect in a dose-dependent manner [55]. The decreased utero-ovarian perfusion in the hypoestrogenic milieu may result in a reduction of the total cumulative exposure of the ovaries to chemotherapeutic agents.

\section{A possible direct effect mediated by ovarian $\mathrm{GnRH}$ receptors}

Human gonads also contain $\mathrm{GnRH}$ receptors, similar to the ovaries of rodents, although at a lower concentration [47,48,57-59]. It has been observed that activation of the ovarian $\mathrm{GnRH}$ receptor may decrease apoptosis in ovarian cancer cells [57]. In another study, GnRHa slowed doxorubicin-induced granulosa cell damage through a $\mathrm{GnRH}$ receptor-mediated mechanism regardless of the hypogonadotropic milieu [60].

\section{Possible upregulation of an antiapoptotic molecule}

Sphingosine-1-phosphate (S1P) has been identified as a sphingolipid metabolite that inhibits ceramide-promoted cell death induced by radiation and chemotherapy in mice $[21,61]$. It has been speculated that GnRHa may upregulate ovarian S1P, thus reducing follicular demise [20]. Oocytes lacking the gene for acid sphingomyelinase, which degrades S1P and generates ceramide, resisted apoptosis induced by doxorubicin in vitro [61]. It has also been observed that S1P exposure prevented cyclophosphamide- and doxorubicin-induced oocyte death in vivo in mice [62]. In a primate study, when S1P or FTY720, an agonistic analog of S1P, was given by direct intraovarian cannulation for a week before ovarian irradiation, rapid resumption of menses and maintenance of ovarian follicles were observed [63]. Nevertheless, there is no experimental evidence regarding whether GnRHa activates the receptors in the ovaries and an intraovarian increase of S1P or other antiapoptotic factors [52].

\section{Possible protection of ovarian germinative stem cells}

Johnson et al. [12,64] demonstrated that rodent ovaries may have mitotically active germ cells that continuously replicate themselves. This finding contradicted the doctrine of reproductive medicine, whereby mammalian females are born with a fixed, determined, and non-increasing reserve of follicles and lose the capacity for germ-cell renewal during fetal life $[12,64,65]$. There is ongoing controversy regarding the existence of germinative stem cells and whether or not the ovaries of adult mammals can generate follicles de novo [66].

In patients undergoing chemotherapy, high menopausal FSH levels and undetectable anti-Müllerian hormone (AMH) levels have been observed. Approximately a year after the chemotherapeutic ovarian insult, FSH concentrations have been shown to decrease to normal levels. In addition, AMH has been found to increase in a large number of patients cotreated with GnRHa [66]. Based on these clinical findings, it has been speculated that administration of GnRHa may interact with these germ cells through some pathways essential for the cell growth and for the activation of PMFs after chemotherapy exposure [66]. 


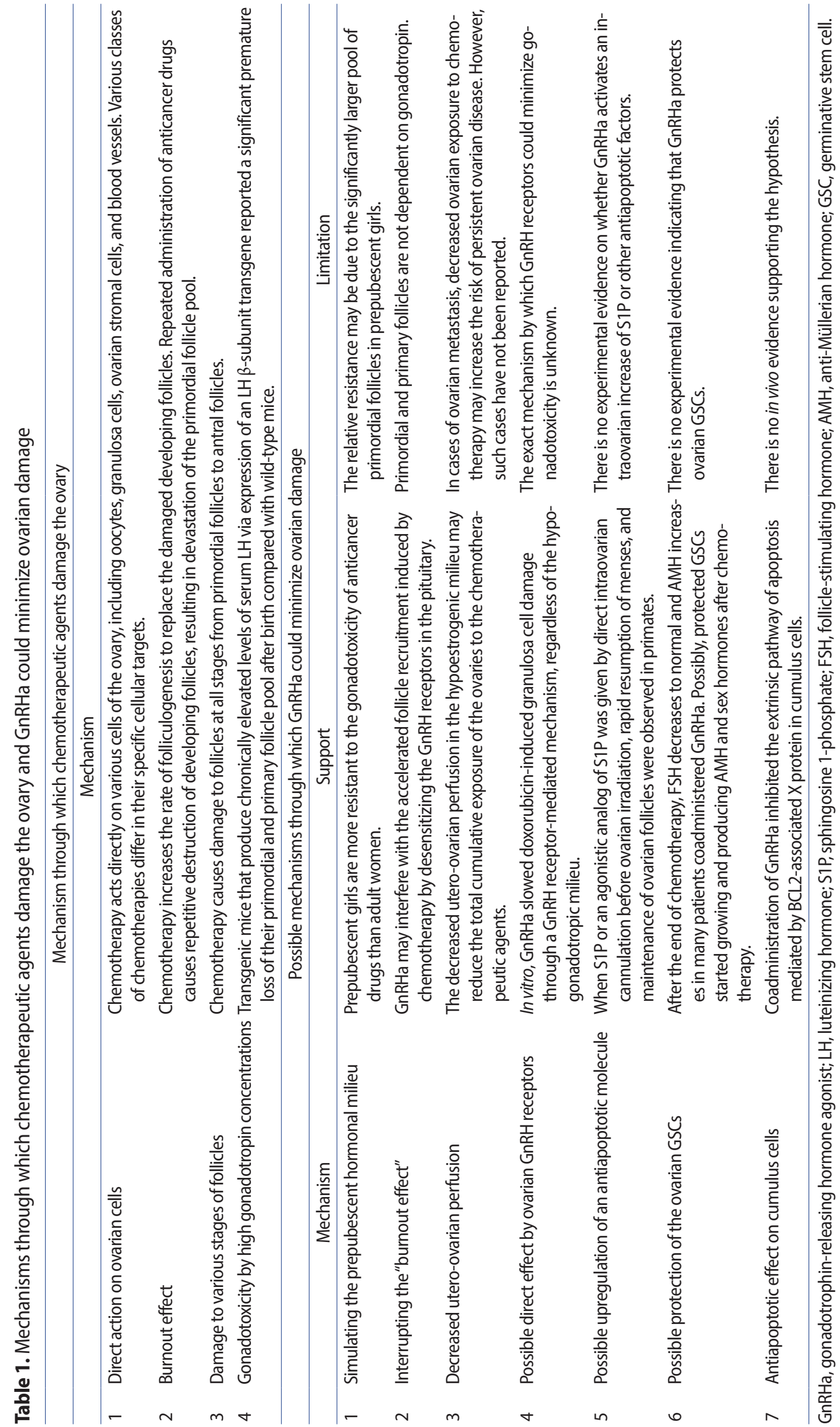




\section{Antiapoptotic effects on cumulus cells}

In a recent study, the effect of GnRHa and cyclophosphamide in the human oocytes and cumulus cell compartments was evaluated using a culture system of ex vivo immature cumulus cell-oocyte complexes [67]. Coadministration of GnRHa inhibited the extrinsic pathway of apoptosis mediated by $\mathrm{BCL} 2$-associated $\mathrm{X}$ protein in cumulus cells, whereas GnRHa did not directly act on oocytes, which do not express $\mathrm{GnRH}$ receptors. The authors suggested that $\mathrm{GnRHa}$ acts directly on cumulus cells to protect the oocytes from chemotherapy by an antiapoptotic effect.

\section{Clinical experiences of GnRHa for fertility preservation}

\section{Recent guidelines for $\mathrm{GnRHa}$ to preserve fertility}

In 2006, the ASCO and the American Society for Reproductive Medicine published the world's first guidelines on fertility preservation in patients with cancer, which was later updated in 2013 and 2018 [2-4]. The 2006 ASCO guidelines stated that cancer patients do not receive sufficient information about fertility preservation options; furthermore, it considered GnRHa as an experimental method of preserving fertility, stressing that cryopreservation of embryos is the standard fertility preservation therapy in women. In addition, the guidelines mentioned that resumption of menstruation does not always reflect maintenance of fertility, meaning that the presence of regular menstrual cycles after cancer treatment is not tantamount to fertility preservation. The basic stance of the ASCO guidelines was maintained through the 2006 and 2013 revisions.

However, there was a remarkable change in the 2018 ASCO guidelines regarding the role of $\mathrm{GnRHa}$ in fertility preservation. The 2018 ASCO guidelines recommended that GnRHa may be offered to patients in the hope of reducing the likelihood of chemotherapy-induced ovarian insufficiency, in case proven fertility preservation methods are not feasible, and in the setting of young women with breast cancer [4]. This change can be interpreted as partially acknowledging the effect of GnRHa on fertility preservation, at least in breast cancer patients.

Most of the guidelines released after 2018 have shown a tendency to follow the ASCO guidelines. In 2020, the Fourth International Consensus Guidelines for Breast Cancer in Young Women by the European School of Oncology and the European Society for Medical Oncology, stated that the concomitant use of GnRHa with adjuvant chemotherapy should be offered to all patients who wish to preserve ovarian function [10]. In this guideline, the limitations of GnRHa were also clearly described, stating that evidence regarding the efficacy of $\mathrm{GnRHa}$ for fertility protection remains insufficient and that GnRHa use during chemotherapy does not replace established fertility pres- ervation methods. In 2018, the British Fertility Society recommended considering the possibility that ovarian suppression with GnRHa should be started immediately before and continued during chemotherapy, as it may partially preserve ovarian function in premenopausal women with early breast cancer. Furthermore, the British Fertility Society guideline recommended that $\mathrm{GnRHa}$ should also be advised to women with non-breast cancer because it is possible that there is a benefit of using GnRHa when other cancers are treated with gonadotoxic chemotherapy [11].

Nonetheless, other guidelines published just a few months before the 2018 ASCO guidelines remained conservative regarding the use of GnRHa in fertility preservation. The National Comprehensive Cancer Network Adolescent and Young Adult Oncology version 2.2018, which focuses on adolescents and young adults with cancer, did not recommend GnRHa as an option for fertility preservation because of insufficient evidence [68]. FertiPROTEKT, a network founded in 2006 for the German-speaking sphere, also published guidelines on fertility preservation for female cancer patients in 2017, stating that GnRH agonists appear to reduce the risk of premature ovarian failure by up to $50 \%$, but the effect is may not be long-lasting [69].

Currently, perceptions of the role of GnRHa as a fertility preservation treatment are evolving. Attention has been drawn to what stance the upcoming Oncofertility Consortium guidelines and guidelines of the International Society for Fertility Preservation will take on GnRHa [70,71].

\section{Recent large-scale RCTs on GnRHa in fertility preservation}

To date, more than 17 RCTs have reported on more than 2,100 patients treated with GnRHa along with chemotherapy (Table 2) [8,7287]. In the early days, the use of GnRHa in preserving fertility showed conflicting results. However, trials since 2013 have reported that the use of GnRHa was relatively helpful for preserving fertility. Crucially, three recent, large prospective RCTs in patients with breast cancer have shown results supporting the use of $\mathrm{GnRHa}$ cotreatment for fertility preservation, which influenced the 2018 ASCO guidelines to partially recognize the effectiveness of $\mathrm{GnRHa}$ in fertility preservation [4].

The first of these RCTs was the Italian PROMISE-GIM6 study, which attempted to evaluate the incidence of chemotherapy-induced early menopause, long-term ovarian function, pregnancy, and prognosis of breast cancer after GnRHa cotreatment with chemotherapy in patients with stage I to III breast cancer [82]. In total, 281 patients, most of whom were hormone receptor (HR)-positive $(n=226)$, were enrolled with a median follow-up of 7.3 years (range, 6.3-8.2 years). The 5-year cumulative incidence estimate of menstrual resumption was higher, with borderline significance, in the GnRHa group (hazard ratio, $1.28 ; 95 \%$ confidence interval $[\mathrm{Cl}], 0.98-1.68 ; p=0.07$ ) and sig- 
Table 2. Randomized controlled trials of gonadotropin-releasing hormone agonists

\begin{tabular}{|c|c|c|c|c|c|c|c|c|}
\hline Study (trial) & $\begin{array}{l}\text { Enrolled } \\
\text { (control) }\end{array}$ & $\begin{array}{l}\text { Evaluable } \\
\text { (control) }\end{array}$ & Type of GnRHa & Disease & $\begin{array}{c}\text { Follow-up } \\
(y r)\end{array}$ & $\begin{array}{l}\text { Primary } \\
\text { outcome }\end{array}$ & $\begin{array}{l}\text { No. of pregnancies } \\
\text { (\%) (GnRHa/control) }\end{array}$ & $p$-value \\
\hline Zhong et al. (2019) [87] & $98(47)$ & $96(45)$ & $\mathrm{G} 3.6 \mathrm{mg}$ & Breast & 1.25 & POF & - & 0.002 \\
\hline Zhang et al. (2018) [86] & $216(108)$ & $170(78)$ & G 3.75 mg, L 11.25 mg & Breast & 4.7 & POF & - & NS \\
\hline Leonard et al. (2017) (OPTION) [85] & $227(121)$ & $202(107)$ & $\mathrm{G} 3.6 \mathrm{mg}$ & Breast & 5 & POV & $9(9) / 6(6)$ & 0.015 \\
\hline Demeestere et al. (2016) [84] & $129(64)$ & $67(35)$ & $\mathrm{T} 11.25 \mathrm{mg}$ & Lymphoma & 5.33 & POF & $17(53.1) / 14(42.8)$ & NS \\
\hline Moore et al. (2015) (POEMS) [83] & $257(131)$ & $218(113)$ & $\mathrm{G} 3.6 \mathrm{mg}$ & Breast & 4.1 & POV & $22(21) / 12(11)$ & 0.04 \\
\hline $\begin{array}{l}\text { Lambertini et al. (2015) } \\
\text { (PROMISE-GIM6) [82] }\end{array}$ & $281(133)$ & $281(133)$ & $\mathrm{T} 3.75 \mathrm{mg}$ & Breast & 7.3 & POV & $8(5) / 3(2)$ & 0.006 \\
\hline Karimi-Zarchi et al. (2014) [81] & $42(21)$ & $42(21)$ & D $3.75 \mathrm{mg}$ & Breast & 0.5 & ROM & - & $<0.001$ \\
\hline Elgindy et al. (2013) [80] & $100(50)$ & $70(37)$ & $\mathrm{T} 3.75 \mathrm{mg}$ & Breast & 1 & ROM & $1(4) / 1(4)$ & NS \\
\hline Song et al. (2013) [79] & $220(110)$ & $183(94)$ & $\mathrm{L}$ & Breast & 1 & POV & - & 0.04 \\
\hline Munster et al. (2012) [78] & $49(22)$ & $47(21)$ & $\mathrm{T}$ & Breast & 1.6 & POV & $0 / 2(10)$ & NS \\
\hline Gerber et al. (2011) (ZORO) [77] & $61(31)$ & $60(30)$ & $\mathrm{G} 3.6 \mathrm{mg}$ & Breast & 4 & ROM & $1(3) / 1(3)$ & NS \\
\hline Behringer et al. (2010) [76] & $23(12)$ & $20(10)$ & $\mathrm{G} 3.6 \mathrm{mg}$ & Lymphoma & 2.1 & POF & - & NR \\
\hline Sverrisdottir et al. (2009) [75] & 285 & $260(123)$ & $\mathrm{G} 3.6 \mathrm{mg}$ & Breast & $\sim 3.0$ & ROM & - & 0.006 \\
\hline Badawy et al. (2009) [74] & $80(40)$ & $78(39)$ & $\mathrm{G} 3.6 \mathrm{mg}$ & Breast & 0.7 & ROM & - & 0.001 \\
\hline Gilani et al. (2007) [73] & $30(15)$ & $30(15)$ & $\mathrm{D} 3.75 \mathrm{mg}$ & Ovary & 0.5 & $\mathrm{FSH}, \mathrm{LH}, \mathrm{E}_{2}$ & - & NR \\
\hline Giuseppe et al. (2007) [72] & $29(15)$ & $29(15)$ & $\mathrm{T} 3.25 \mathrm{mg}, 11.25 \mathrm{mg}$ & Lymphoma & 3.59 & ROM & $0(14) / 2(15)$ & NR \\
\hline Waxman et al. (1987) [8] & $18(10)$ & $18(10)$ & B (nasal) & Lymphoma & 2 & ROM & - & NR \\
\hline
\end{tabular}

GnRHa, gonadotrophin-releasing hormone agonist; G, goserelin; L, leuprorelin; T, triptorelin; D, Diphereline; B, buserelin; POF, premature ovarian failure; POV, preservation of ovarian function; ROM, resumption of menses; FSH, follicle-stimulating hormone; LH, luteinizing hormone; $\mathrm{E}_{2}$, estradiol; OPTION, Ovarian Protection Trial In Premenopausal Breast Cancer Patients; POEMS, Prevention of Early Menopause Study; PROMISE-GIM6, Prevention of Menopause Induced by Chemotherapy: A Study in Early Breast Cancer Patients-Gruppo Italiano Mammella 6; ZORO, Zoladex Rescue of Ovarian function; NS, not significant; NR, not reported.

nificantly higher after adjustment for age (hazard ratio, 1.48; $95 \% \mathrm{Cl}$, $1.12-1.95 ; p=0.006)$. Eight pregnancies occurred in the GnRHa group and 3 in the control group, which was not a statistically significant difference (hazard ratio, 2.56; $95 \% \mathrm{Cl}, 0.68-9.60$ ). Contrary to concerns, the 5 -year disease-free survival rate in the GnRHa group was comparable to that of the control group (GnRHa vs. control: hazard ratio, 1.17; 95\% Cl, 0.72-1.92). A similar result was reported in a subgroup analysis of patients with HR-positive disease.

The Prevention of Early Menopause Study (POEMS)-The Southwest Oncology Group (SWOG)/S0230 study in the United States enrolled only HR-negative breast cancer patients, and demonstrated a statistically significant reduction in ovarian failure rate in the $\mathrm{GnRHa}$ arms 24 months after chemotherapy (odds ratio [OR], 0.30; 95\% Cl, 0.09$0.97 ; p=0.04$ ). Remarkably, the POEMS-SWOG/S0230 study presented pregnancy rates [83]. In the GnRHa arm, 25 patients attempted pregnancy, 22 achieved clinical pregnancy, and 18 babies were born. In the control group, 18 patients attempted pregnancy, 12 achieved clinical pregnancy, and 12 babies were born. Significantly higher live birth and ongoing pregnancy rates were observed in the GnRHa arm (OR, 2.45; 95\% Cl, 1.09-5.51; $p=0.03$ ). Although this study included only patients with HR-negative breast cancer, women in the $\mathrm{GnRHa}$ group also showed improved disease-free survival (hazard ratio, 0.49; $95 \% \mathrm{Cl}, 0.24-0.97 ; p=0.04$ ) and overall survival (hazard ratio, 0.43;
$95 \% \mathrm{Cl}, 0.18-1.00 ; p=0.05)$.

Meanwhile, the third large, prospective study, the Anglo Celtic Group OPTION trial, examined the effect of GnRHa administration before and during chemotherapy to 202 stage I to IIIB breast cancer patients, including 95 HR-positive subjects [85]. The primary outcome was amenorrhea between 12 and 24 months after randomization, combined with elevated FSH levels. This RCT found that GnRHa reduced the prevalence of amenorrhea to $22 \%$ between 12 and 24 months (vs. 38\% in the control group; $p=0.015$ ) and the prevalence of $\mathrm{POI}$ to $18.5 \%$ (vs. $34.8 \%$ in the control group; $p=0.048$ ). FSH concentrations were also found to be lower in all women treated with GnRHa at both 12 and 24 months ( $p=0.027$ and $p=0.001$, respectively). An assessment of ovarian reserve using $\mathrm{AMH}$ showed a marked fall in both groups during treatment to median values of $5 \%$ of pretreatment levels in the control group and $7 \%$ in the goserelin group, which were not significantly different between groups. In subgroup analysis by age group, GnRHa demonstrated a significantly reduced risk of $\mathrm{POI}$ only in women younger than 40 years.

\section{Meta-analyses and systematic reviews on GnRHa in fertility preservation}

Comparing multiple RCTs through meta-analyses (MAs) or systematic reviews (SRs) will aid in determining directions of future research. 
In recent years, several MAs and SRs have been published (Table 3), including the recently released RCTs described above. A number of recent RCTs have reported favorable effects of $\mathrm{GnRHa}$ on the prevention of chemotherapy-induced POI. Therefore, recent MAs and SRs, including the Cochrane review released in 2019, have also reported results in favor of adjuvant use of $\mathrm{GnRHa}$ with chemotherapy. In this section, we will review the areas that need to be clarified regarding the role of $\mathrm{GnRHa}$ in fertility preservation by comparing MAs and SRs published in the last 5 years.

\section{Lack of a standardized definition of POI after chemotherapy}

The lack of a standardized definition of chemotherapy-associated POI has been identified in several MAs as a limitation to the interpretation of findings in the literature regarding GnRHa. All MAs covered in this review analyzed the amenorrhea rate or resumption of menses as the primary outcome and the rate of spontaneous pregnancy as the secondary outcome, except for two studies [88,89]. Three studies assessed the results of the primary endpoint without setting a specific time point [90-92], one study analyzed the primary outcome 2 years after completion of treatment [88], and the remaining studies included analyses of the primary outcome at 1 year after the end of chemotherapy [89,93-96]. The rate of amenorrhea 1 year after the end of chemotherapy is a commonly adopted primary endpoint in several RCTs $[79,80,82,86,87]$ because menopause is clinically defined as the absence of menstruation for a year, and resumption of menses is a clinically relevant and reproducible outcome [93].

However, resumption of menses does not necessarily translate into restoration of fertility [93]. Oktay and Turan [97] emphasized that menstruation or amenorrhea should not be considered surrogate markers of $\mathrm{GnRHa}$ efficacy in preserving the ovarian reserve. However, owing to the lack of data related to pregnancy, controversy remains as to whether $\mathrm{GnRHa}$ administration will really help future pregnancies in premenopausal women receiving chemotherapy. Ten SRs and MAs have been published in the past 5 years, seven of which have reported results on pregnancy outcomes. Five of the seven MAs found significantly higher rates of pregnancy in patients receiving chemotherapy and $\mathrm{GnRHa}$ than in those receiving chemotherapy alone [90,91,93-95]. In particular, studies that included only breast cancer patients showed clearer results for efficacy of GnRHa on the spontaneous pregnancy rate after chemotherapy [90,93-95]. However, as Munhoz et al. [94] noted in their MA, these analyses of pregnancy rates are closer to exploratory analyses than to a valid endpoint for a main analysis. The results of pregnancy outcomes in MAs might be affected by several biases. First, although pregnancy may be the most specific indicator of gonadal function, subfertility can be multifactorial, and inability to conceive does not necessarily indicate

Table 3. The past 5 years' meta-analyses and systematic reviews regarding the fertility preservation efficacy of GnRH agonists during chemotherapy

\begin{tabular}{|c|c|c|c|c|c|c|c|c|}
\hline Study & $\begin{array}{c}\text { No. of } \\
\text { included } \\
\text { studies }\end{array}$ & $\begin{array}{c}\mathrm{RCT} \\
\text { addressing } \\
\text { pregnancy }\end{array}$ & $\begin{array}{l}\text { No. of } \\
\text { patients }\end{array}$ & Disease & $\mathrm{OR}(95 \% \mathrm{Cl})$ & $\begin{array}{c}p \text {-value for } \\
\text { POF, POV, ROM }\end{array}$ & $\mathrm{OR}(95 \% \mathrm{Cl})$ & $\begin{array}{l}p \text {-value for } \\
\text { pregnancy }\end{array}$ \\
\hline $\begin{array}{c}\text { Sofiyeva et al. } \\
\text { (2019) [89] }\end{array}$ & 18 & 5 & 1,043 & Breast, SLE, hematological malignancy & $1.38^{\mathrm{a})}(1.18-1.63)$ & $<0.0001$ & & - \\
\hline $\begin{array}{l}\text { Chen et al. } \\
\text { (2019) [96] }\end{array}$ & 12 & 7 & 1,369 & Breast, ovary, lymphoma & $0.44^{\mathrm{a})}(0.31-0.61)$ & $<0.00001$ & $1.59^{\text {a) }}(0.93-2.70)$ & 0.09 \\
\hline $\begin{array}{c}\text { Hickman et al. } \\
\text { (2018) [88] }\end{array}$ & 10 & 7 & 1,051 & Breast, ovary, lymphoma & $1.83(1.34-2.49)$ & NR & & - \\
\hline $\begin{array}{l}\text { Senra et al. } \\
\text { (2018) [91] }\end{array}$ & 13 & 9 & 1,208 & Breast, lymphoma & $0.6^{\mathrm{a})}(0.45-0.79)$ & 0.0004 & $1.43^{\mathrm{a})}(1.01-2.02)$ & 0.04 \\
\hline $\begin{array}{l}\text { Lambertini et al. } \\
\text { (2018) [95] }\end{array}$ & 5 & 3 & 847 & Breast & $0.38(0.26-0.57)$ & $<0.001$ & $1.83^{b)}(1.06-3.15)$ & 0.03 \\
\hline $\begin{array}{l}\text { Bai et al. } \\
\text { (2017) [90] }\end{array}$ & 15 & 5 & 1,540 & Breast & $1.36(1.19-1.56)$ & $<0.00001$ & $1.9(1.06-3.41)$ & 0.03 \\
\hline $\begin{array}{c}\text { Munhoz et al. } \\
\text { (2016) [94] }\end{array}$ & 7 & NR & 1,047 & Breast & $2.41(1.40-4.15)$ & 0.002 & $2.41(1.02-3.36)$ & 0.04 \\
\hline $\begin{array}{r}\text { Elgindy et al. } \\
\text { (2015) [92] }\end{array}$ & 10 & 8 & 427 & Breast, ovary, lymphoma & $1.12^{\text {a) }}(0.99-1.27)$ & NS & $1.63^{\mathrm{a})}(0.94-2.82)$ & NS \\
\hline $\begin{array}{l}\text { Lambertini et al. } \\
\text { (2015) [93] }\end{array}$ & 12 & 5 & 359 & Breast & $0.36(0.23-0.57)$ & $<0.001$ & $1.83(1.02-3.28)$ & 0.04 \\
\hline
\end{tabular}

$\mathrm{GnRH}$, gonadotropin-releasing hormone; RCT, randomized controlled trial; OR, odds ratio; Cl, confidence interval; POF, premature ovarian failure; POV, preservation of ovarian function; ROM, resumption of menses; SLE, systemic lupus erythematosus; NR, not reported; NS, not significant.

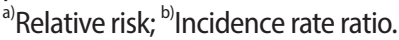


hypogonadism [88]. Second, limited information is available on the number of patients interested in future pregnancies at the time of randomization and on those who attempted to become pregnant [91]. Only one of the RCTs reported the number of women attempting pregnancy and calculated the pregnancy rate for this subgroup [83]. Therefore, most MAs used the number of the entire randomized population as the denominator for comparing pregnancy outcomes, rather than the number of women who actually attempted pregnancy. However, multiple biases are also possible when using the number of patients attempting pregnancy as a denominator for the pregnancy rate. For example, without blinding, intervention assignment can affect the likelihood of attempting pregnancy. In addition, because a significantly lower rate of participants developed POI in the group administered $\mathrm{GnRHa}$, the intervention itself had an effect on the size of the group in which attempting pregnancy was possible. Furthermore, as observed in the POEMS-SWOG/S0230 study, some pregnancies might occur in women who did not attempt pregnancy [83]. Finally, the study period of the RCTs included in the MAs varied. A short median follow-up of the studies might be a possible explanation of the limited number of pregnancies observed, especially in trials including patients with HR-positive disease who received adjuvant endocrine therapy for at least 5 years [78,82,85], thus delaying attempts for pregnancy.

\section{Gonadotoxicity by cancer type and chemotherapy regimen}

GnRHa was recently reported to be effective in RCTs including breast cancer patients [74,75,79,81-83,85,87], whereas GnRHa was found to be ineffective in preserving fertility in a large-scale RCT targeting only lymphoma patients [84]. Conflicting results have been reported in MAs. Elgindy et al. [80] observed that GnRHa administration during chemotherapy did not protect the ovaries from gonadal toxicity regardless of cancer type. Senra et al. [91] reported that Gn$\mathrm{RHa}$ had a significant benefit on the risk of POI in breast cancer patients (relative risk [RR], $0.57 ; 95 \% \mathrm{Cl}, 0.43-0.77$ ), but not in lymphoma patients (RR, 0.70; 95\% Cl, 0.20-2.47). Meanwhile, Sofiyeva et al. [89] observed a gonadoprotective effect of $\mathrm{GnRHa}$ in both hematological malignancies (RR, 1.77; 95\% Cl, 1.15-2.74) and breast cancer (RR, 1.31; 95\% Cl, 1.05-1.62).

In fact, the difference in the efficacy of GnRHa may not be attributable to the type of cancer, but rather to the regimen of chemotherapy used for each cancer type. It is well known that gonadotoxicity varies depending on the type of chemotherapeutic agent and the duration of administration [2]. To overcome this heterogeneity, some early RCTs enrolled only those who received the same anticancer regimen to evaluate the efficacy of $\mathrm{GnRHa}$ [74-76]. However, unlike in RCTs, it is difficult to control the different anticancer regimens and different administration periods of the studies included in MAs. Several MAs have reported inconsistent results for risk of POI after administering different regimens and agents. A recent MA found that women exposed to taxanes demonstrated a lower rate of menstrual recovery than those treated with chemotherapy regimens that did not contain taxanes (OR, 0.49; 95\% Cl, 0.30-0.80; $p=0.004)$ [98]. In another MA that included only early breast cancer patients who were administered GnRHa for the purpose of fertility preservation, whether or not a taxane was included in the anticancer regimen was not an independent variable associated with the risk of developing chemotherapy-induced POI [95]. In the same MA, the duration of chemotherapy ( $>4$ months) was also not associated with the risk of POI [95].

In another MA including breast cancer and lymphoma patients [91], when all patients were subdivided according to chemotherapy regimen into high toxicity and low to medium toxicity groups, the benefit of $\mathrm{GnRHa}$ therapy in preventing POI appeared to be of a greater magnitude among women treated with low- to medium-toxicity chemotherapy (RR, 0.49; $95 \% \mathrm{Cl}, 0.29-0.84)$; this is in comparison to women treated with highly toxic chemotherapy $(R R, 0.66$; $95 \% \mathrm{Cl}, 0.45-0.96)$. The major mechanism of ovarian protection by $\mathrm{GnRHa}$ is believed to be the downregulation of pituitary $\mathrm{GnRH}$ receptors with a drastic reduction of serum gonadotropin levels and blocking of follicular recruitment $[91,99]$. The authors assumed that the reason for a weaker protection of GnRHa against highly toxic chemotherapy was that these agents cause ovarian damage through multiple mechanisms beyond follicle destruction, such as cortical fibrosis, vascular lesions, and accelerated atresia [91,100].

\section{Time to recovery of ovarian function after chemotherapy}

To date, there is a paucity of data available on the appropriate follow-up period to observe recovery of ovarian function after anticancer treatment. The difference in follow-up duration between groups [101] and between studies is a another possible source of heterogeneity and bias in the studies selected for MAs, which in turn could impact the chance of $\mathrm{POI}$ diagnosis and pregnancy outcomes [93]. Although there are several RCTs with a follow-up duration of 1 year after the end of chemotherapy, recent large-scale RCTs tended to have a follow-up duration of 2 years or more [75,78,82-84]. Recently, as RCTs have included HR-positive breast cancer patients, the study period has also been growing longer. In a trial by Lambertini et al. [82], because patients with HR-positive breast cancer were included, patients were followed up for more than 5 years to avoid endocrine treatment masking resumption of menses (mean follow-up, 7.3 
years) . Moreover, an RCT showed different results within 2 years of follow-up compared with follow-up for only 1 year. For example, Sverrisdottir et al. [75] have observed that the proportion of menstruating women in the GnRHa group showed a statistically significant increase between 24 and 36 months, in contrast to all the other groups in which menses were unchanged or decreasing in the study. A short follow-up period may be responsible for discrepancies between studies, leading to premature conclusions [102].

The time at which ovarian function was evaluated has varied widely [88]. Therefore, several MAs have analyzed the outcomes at various time points, except for three studies that did not set a specific time point for assessing outcomes [90-92]. Eight MAs out of the nine studies in listed in Table 3 found a positive impact on preservation of ovarian function with GnRHa treatment compared with chemotherapy alone. Meanwhile, three of the eight MAs reported that the benefits of GnRHa administration may change over time [88,95,96]. Hickman et al. [88] reported that the effect of GnRHa treatment on ovarian protection was not valid after 2 years $(\mathrm{OR}, 0.53 ; 95 \% \mathrm{Cl}, 0.22-$ 1.30). Chen et al. [96] also reported no difference during a follow-up period longer than 12 months between the GnRHa group and controls (RR, 1.08; 95\% Cl, 0.95-1.22). Meanwhile, the incidence of menstrual recovery was significantly higher in the GnRHa group during a follow-up period no longer than 12 months, with an overall effect favoring treatment with $\mathrm{GnRHa}(\mathrm{RR}, 1.60 ; 95 \% \mathrm{Cl}, 1.14-2.24 ; p=0.006)$. However, an MA by Lambertini et al. [95] presented a non-significantly reduced risk of amenorrhea at 1 year after chemotherapy (OR, $0.92 ; 95 \% \mathrm{Cl}, 0.66-1.28 ; p=0.623)$. However, they found a significantly reduced risk at 2 years $(\mathrm{OR}, 0.51 ; 95 \% \mathrm{Cl}, 0.31-0.85 ; p=0.009)$. Thus far, the duration of benefits from GnRHa cotreatment appears to be unclear and requires further study.

\section{Age of the patient at the time of treatment}

Age has been identified as a major determinant of the risk of $\mathrm{POI}$ after chemotherapy [98,103]. This age-related difference is most likely a result of the reduction of the PMF pool with aging, resulting in an increase in the risk of developing ovarian failure and infertility in older women after cytotoxic treatment, even at smaller doses [104]. According to recent MAs, this tendency is prominent in patients 40 years and older $[89,90,95,98]$. Patient age for eligibility varies considerably across trials, and only four RCTs set age limitations for eligibility to 40 years $[74,76,80,85]$. In the studies by Song et al. [79] and Munster et al. [78], the mean patient age was 41 and 45 years, respectively, which may have contributed to diminished recovery. Future clinical trials verifying the efficacy of GnRHa for ovarian protection should be designed considering the patient's age.

\section{Hormonal receptor status in breast cancer patients}

There have been safety concerns regarding the potential negative effect of the concurrent use of tamoxifen with chemotherapy based on preclinical and clinical evidence [93,105-107]. However, GnRHa has been found to have different pharmacodynamic properties from those of tamoxifen. Since the 1990s, there have been randomized studies that investigated the impact of concurrent ovarian function suppression (obtained pharmacologically or with surgery or radiotherapy) with chemotherapy, and these findings did not demonstrate differences in patients' prognoses [108-110]. Moreover, in recently published trials, excellent survival outcomes were reported with the use of GnRHa concomitantly with chemotherapy in patients, including HR-positive patients $[82,83,86,111]$. In an MA by Lambertini et al. [82], no difference was noted in the prognosis of breast cancer according to HR status when GnRHa was co-administered. An analysis according to HR status showed no significant interaction $\left(p_{\text {interaction }}=0.762\right)$; and the adjusted hazard ratios for disease-free survival were $0.79(95 \% \mathrm{Cl}, 0.24-2.59)$ and $0.65(95 \% \mathrm{Cl}$, 0.39-1.07) in patients with HR-positive and HR-negative disease, respectively. According to these favorable results, the OPTION trial amended its protocol to allow enrollment of women with HR-positive tumors [85]. The original protocol of the OPTION trial restricted enrollment to only those with HR-negative tumors.

It has also been speculated that GnRHa will not have an ovarian-protective effect on HR-positive breast cancers [112]. However, recent trials that included HR-positive breast cancer patients demonstrated favorable outcomes in preventing $\mathrm{POI}$ through the concurrent use of GnRHa with chemotherapy $[75,79,82,85,86]$. In an MA by Senra et al. [91], HR status was determined not to influence the effect of $\mathrm{GnRHa}$ on the risk for $\mathrm{POI}$, which was comparable among women with receptor-positive $(\mathrm{RR}, 0.69 ; 95 \% \mathrm{Cl}, 0.48-1.00)$ and receptor-negative (RR, $0.62 ; 95 \% \mathrm{Cl}, 0.33-1.14)$ tumors.

However, opinions still vary among guidelines. Although the St. Gallen International Expert Consensus [113] and the National Comprehensive Cancer Network Guidelines [112] have recommended the use of GnRHa only for patients with HR-negative breast cancer, the Breast Cancer in Young Women-2 Panel concluded that a protective effect was likely in both HR-negative and HR-positive patients, without an increased risk of breast cancer recurrence [114]. Recent findings further support the position that GnRHa has an ovarian protection effect in breast cancer patients regardless of $\mathrm{HR}$ status. 


\section{AMH as a surrogate marker for fertility in patients who have undergone chemotherapy}

Several studies have reported that AMH was an accurate biomarker for assessing the extent of ovarian damage after chemotherapy [115120]. Dunlop and Anderson [115] found that pretreatment AMH can predict $\mathrm{POI}$ or ongoing ovarian activity after chemotherapy. Despite the fact that the values of AMH fluctuate before 25 years of age in women, there are reports that $\mathrm{AMH}$ may be of value for assessing ovarian function in prepubertal girls after cancer treatment $[116,117]$. Thus, some trials have analyzed AMH as a secondary outcome to examine the ovary-protective effect of GnRHa $[72,76,77,80,85]$.

However, some researchers are skeptical regarding the role of $\mathrm{AMH}$ in predicting chemotherapy-associated ovarian dysfunction. It is well known that $\mathrm{AMH}$ does not predict spontaneous pregnancy. A recent prospective time-to-pregnancy cohort study including 750 women between the ages of 30 and 44 found no association between AMH levels and rates of spontaneous conception [121]. Similarly, a retrospective study showed that AMH levels did not accurately predict pregnancy in breast cancer patients who underwent chemotherapy [122]. As in the study of Demeestere et al. [84], in which five patients with protocol-defined $\mathrm{POI}$ became pregnant during follow-up, low AMH levels do not necessarily indicate infertility. In addition, patients who have undergone ovarian tissue cryopreservation often have nearly undetectable AMH levels, but decent pregnancy rates have been reported [123].

Currently, no MAs have analyzed AMH levels as an outcome. The RCTs by Giuseppe et al. [72], Elgindy et al. [80], and Leonard et al. [85] reported that there was no difference in changes of AMH levels after chemotherapy between the GnRHa group and controls, and Gerber et al. [77] reported incomplete data regarding AMH. Meanwhile, an $\mathrm{RCT}$ by Leonard et al. [85] reported that AMH levels before chemotherapy were a predictor of posttreatment amenorrhea $(p<0.001)$. However, after adjustment for age, the effect of pretreatment AMH was no longer significant.

\section{Conclusion}

In the early days, the use of GnRHa for preserving fertility showed conflicting results. However, recent trials have reported that the use of $\mathrm{GnRHa}$ is helpful in preventing POI following chemotherapy, at least in breast cancer patients, owing to the overall increase in the number of patients enrolled in trials and the longer follow-up periods. In our opinion, all young women (even patients with high-risk leukemia) facing gonadotoxic chemotherapy should be counselled about and offered various options for fertility preservation, including both GnRHa and cryopreservation of embryos, oocytes, and ovarian tissue.

However, it remains unclear to what extent GnRHa coadministration could provide benefits for achieving pregnancy after chemotherapy. In general, attempting pregnancy after cancer treatment must be delayed until chemotherapy is out of the patient's system and the patient is at a low risk of recurrence. Experts suggest that the timing of pregnancy should be individualized $[88,124]$. In patients with HR-positive breast cancer who wish to become pregnant, it may be more difficult to decide when to attempt pregnancy, because these patients are typically treated with tamoxifen for 5 to 10 years $[88,124]$. The POSITIVE study is currently underway to determine the safety of an interruption in endocrine therapy to allow childbearing, and the results of this ongoing research have attracted significant attention.

\section{Conflict of interest}

No potential conflict of interest relevant to this article was reported.

\section{ORCID}

Jae Hoon Lee

https://orcid.org/0000-0003-4223-1395

Young Sik Choi

https://orcid.org/0000-0002-1157-4822

\section{Author contributions}

Conceptualization, data curation, Formal analysis: all authors. Writing-original draft: JHL. Writing-review \& editing:YSC.

\section{References}

1. Jung KW, Won YJ, Kong HJ, Lee ES. Cancer statistics in Korea: incidence, mortality, survival, and prevalence in 2016. Cancer Res Treat 2019;51:417-30.

2. Lee SJ, Schover LR, Partridge AH, Patrizio P, Wallace WH, Hagerty K, et al. American Society of Clinical Oncology recommendations on fertility preservation in cancer patients. J Clin Oncol 2006;24: 2917-31.

3. Loren AW, Mangu PB, Beck LN, Brennan L, Magdalinski AJ, Partridge $\mathrm{AH}$, et al. Fertility preservation for patients with cancer: American Society of Clinical Oncology clinical practice guideline update. J Clin Oncol 2013;31:2500-10.

4. Oktay K, Harvey BE, Partridge AH, Quinn GP, Reinecke J, Taylor HS, et al. Fertility preservation in patients with cancer: ASCO clinical practice guideline update. J Clin Oncol 2018:36:1994-2001.

5. Letourneau JM, Ebbel EE, Katz PP, Oktay KH, McCulloch CE, Ai WZ, et al. Acute ovarian failure underestimates age-specific reproduc- 
tive impairment for young women undergoing chemotherapy for cancer. Cancer 2012;118:1933-9.

6. Glode LM, Robinson J, Gould SF. Protection from cyclophosphamide-induced testicular damage with an analogue of gonadotropin-releasing hormone. Lancet 1981;1:1132-4.

7. Ortin TT, Shostak CA, Donaldson SS. Gonadal status and reproductive function following treatment for Hodgkin's disease in childhood: the Stanford experience. Int J Radiat Oncol Biol Phys 1990;19:873-80.

8. Waxman JH, Ahmed R, Smith D, Wrigley PF, Gregory W, Shalet S, et al. Failure to preserve fertility in patients with Hodgkin's disease. Cancer Chemother Pharmacol 1987;19:159-62.

9. Blumenfeld Z, Evron A. Preserving fertility when choosing chemotherapy regimens: the role of gonadotropin-releasing hormone agonists. Expert Opin Pharmacother 2015;16:1009-20.

10. Paluch-Shimon S, Cardoso F, Partridge AH, Abulkhair O, Azim HA Jr, Bianchi-Micheli G, et al. ESO-ESMO 4th International Consensus Guidelines for Breast Cancer in Young Women (BCY4). Ann Oncol 2020;31:674-96.

11. Yasmin E, Balachandren N, Davies MC, Jones GL, Lane S, Mathur R, et al. Fertility preservation for medical reasons in girls and women: British fertility society policy and practice guideline. Hum Fertil (Camb) 2018;21:3-26.

12. Johnson J, Canning J, Kaneko T, Pru JK, Tilly JL. Germline stem cells and follicular renewal in the postnatal mammalian ovary. Nature 2004:428:145-50.

13. Wallace WH, Kelsey TW. Human ovarian reserve from conception to the menopause. PLoS One 2010;5:e8772.

14. Morgan S, Anderson RA, Gourley C, Wallace WH, Spears N. How do chemotherapeutic agents damage the ovary? Hum Reprod Update 2012;18:525-35.

15. Chiarelli AM, Marrett LD, Darlington G. Early menopause and infertility in females after treatment for childhood cancer diagnosed in 1964-1988 in Ontario, Canada. Am J Epidemiol 1999; 150:245-54.

16. Petrek JA, Naughton MJ, Case LD, Paskett ED, Naftalis EZ, Singletary SE, et al. Incidence, time course, and determinants of menstrual bleeding after breast cancer treatment: a prospective study. J Clin Oncol 2006;24:1045-51.

17. Kalich-Philosoph L, Roness H, Carmely A, Fishel-Bartal M, Ligumsky H, Paglin S, et al. Cyclophosphamide triggers follicle activation and "burnout"; AS101 prevents follicle loss and preserves fertility. Sci Transl Med 2013;5:185ra62.

18. Gavish Z, Peer G, Roness H, Cohen Y, Meirow D. Follicle activation and 'burn-out' contribute to post-transplantation follicle loss in ovarian tissue grafts: the effect of graft thickness. Hum Reprod 2014;29:989-96.
19. Blumenfeld Z, Evron A. Endocrine prevention of chemotherapy-induced ovarian failure. Curr Opin Obstet Gynecol 2016;28: 223-9.

20. Blumenfeld Z, von Wolff M. GnRH-analogues and oral contraceptives for fertility preservation in women during chemotherapy. Hum Reprod Update 2008;14:543-52.

21. Perez Gl, Knudson CM, Leykin L, Korsmeyer SJ, Tilly JL. Apoptosis-associated signaling pathways are required for chemotherapy-mediated female germ cell destruction. Nat Med 1997;3: 1228-32.

22. Jurisicova A, Lee HJ, D’Estaing SG, Tilly J, Perez Gl. Molecular requirements for doxorubicin-mediated death in murine oocytes. Cell Death Differ 2006;13:1466-74.

23. Bar-Joseph H, Ben-Aharon I, Rizel S, Stemmer SM, Tzabari M, Shalgi R. Doxorubicin-induced apoptosis in germinal vesicle (GV) oocytes. Reprod Toxicol 2010;30:566-72.

24. Gonfloni S, Di Tella L, Caldarola S, Cannata SM, Klinger FG, Di Bartolomeo C, et al. Inhibition of the c-Abl-TAp63 pathway protects mouse oocytes from chemotherapy-induced death. Nat Med 2009;15:1179-85.

25. Ben-Aharon I, Bar-Joseph H, Tzarfaty G, Kuchinsky L, Rizel S, Stemmer SM, et al. Doxorubicin-induced ovarian toxicity. Reprod Biol Endocrinol 2010;8:20.

26. Utsunomiya T, Tanaka T, Utsunomiya H, Umesaki N. A novel molecular mechanism for anticancer drug-induced ovarian failure: irinotecan $\mathrm{HCl}$, an anticancer topoisomerase I inhibitor, induces specific FasL expression in granulosa cells of large ovarian follicles to enhance follicular apoptosis. Int J Oncol 2008;32:991-1000.

27. Zhao XJ, Huang YH, Yu YC, Xin XY. GnRH antagonist cetrorelix inhibits mitochondria-dependent apoptosis triggered by chemotherapy in granulosa cells of rats. Gynecol Oncol 2010;118:69-75.

28. Meirow D, Dor J, Kaufman B, Shrim A, Rabinovici J, Schiff E, et al. Cortical fibrosis and blood-vessels damage in human ovaries exposed to chemotherapy: potential mechanisms of ovarian injury. Hum Reprod 2007;22:1626-33.

29. Marcello MF, Nuciforo G, Romeo R, Di Dino G, Russo I, Russo A, et al. Structural and ultrastructural study of the ovary in childhood leukemia after successful treatment. Cancer 1990;66:2099-104.

30. Soleimani R, Heytens E, Darzynkiewicz Z, Oktay K. Mechanisms of chemotherapy-induced human ovarian aging: double strand DNA breaks and microvascular compromise. Aging (Albany NY) 2011:3:782-93.

31. Matzuk MM, Burns KH, Viveiros MM, Eppig JJ. Intercellular communication in the mammalian ovary: oocytes carry the conversation. Science 2002;296:2178-80.

32. Petrillo SK, Desmeules P, Truong TQ, Devine PJ. Detection of DNA damage in oocytes of small ovarian follicles following phosphor- 
amide mustard exposures of cultured rodent ovaries in vitro. Toxicol Appl Pharmacol 2011;253:94-102.

33. Desmeules P, Devine PJ. Characterizing the ovotoxicity of cyclophosphamide metabolites on cultured mouse ovaries. Toxicol Sci 2006;90:500-9.

34. Oktem O, Oktay K. Quantitative assessment of the impact of chemotherapy on ovarian follicle reserve and stromal function. Cancer 2007;110:2222-9.

35. Abir R, Ben-Haroush A, Felz C, Okon E, Raanani H, Orvieto R, et al. Selection of patients before and after anticancer treatment for ovarian cryopreservation. Hum Reprod 2008;23:869-77.

36. Smith ML, Kumar MA. The "two faces" of tumor suppressor p53-revisited. Mol Cell Pharmacol 2010;2:117-9.

37. Downs SM, Utecht AM. Metabolism of radiolabeled glucose by mouse oocytes and oocyte-cumulus cell complexes. Biol Reprod 1999;60:1446-52.

38. Siddik ZH. Cisplatin: mode of cytotoxic action and molecular basis of resistance. Oncogene 2003;22:7265-79.

39. Gonfloni S. DNA damage stress response in germ cells: role of c-Abl and clinical implications. Oncogene 2010;29:6193-202.

40. Flaws JA, Abbud R, Mann RJ, Nilson JH, Hirshfield AN. Chronically elevated luteinizing hormone depletes primordial follicles in the mouse ovary. Biol Reprod 1997;57:1233-7.

41. Lobo RA. Potential options for preservation of fertility in women. N Engl J Med 2005;353:64-73.

42. Patsoula E, Loutradis D, Drakakis P, Michalas L, Bletsa R, Michalas S. Messenger RNA expression for the follicle-stimulating hormone receptor and luteinizing hormone receptor in human oocytes and preimplantation-stage embryos. Fertil Steril 2003;79:118793.

43. Zheng W, Magid MS, Kramer EE, Chen YT. Follicle-stimulating hormone receptor is expressed in human ovarian surface epithelium and fallopian tube. Am J Pathol 1996;148:47-53.

44. Knight PG, Glister C. TGF-beta superfamily members and ovarian follicle development. Reproduction 2006;132:191-206.

45. Babu PS, Danilovich N, Sairam MR. Hormone-induced receptor gene splicing: enhanced expression of the growth factor type I follicle-stimulating hormone receptor motif in the developing mouse ovary as a new paradigm in growth regulation. Endocrinology 2001;142:381-9.

46. Adriaens I, Cortvrindt R, Smitz J. Differential FSH exposure in preantral follicle culture has marked effects on folliculogenesis and oocyte developmental competence. Hum Reprod 2004;19:398408.

47. Edson MA, Nagaraja AK, Matzuk MM. The mammalian ovary from genesis to revelation. Endocr Rev 2009;30:624-712.

48. Webb R, Garnsworthy PC, Gong JG, Armstrong DG. Control of fol- licular growth: local interactions and nutritional influences. J Anim Sci 2004;82 E-Suppl:E63-74.

49. Patel H, Bhartiya D, Parte S, Gunjal P, Yedurkar S, Bhatt M. Follicle stimulating hormone modulates ovarian stem cells through alternately spliced receptor variant FSH-R3. J Ovarian Res 2013;6:52.

50. Oktay K, Briggs D, Gosden RG. Ontogeny of follicle-stimulating hormone receptor gene expression in isolated human ovarian follicles. J Clin Endocrinol Metab 1997;82:3748-51.

51. Chapman RM, Sutcliffe SB. Protection of ovarian function by oral contraceptives in women receiving chemotherapy for Hodgkin's disease. Blood 1981;58:849-51.

52. Poggio F, Lambertini M, Bighin C, Conte B, Blondeaux E, D'Alonzo A, et al. Potential mechanisms of ovarian protection with gonadotropin-releasing hormone agonist in breast cancer patients: a review. Clin Med Insights Reprod Health 2019;13:1179558119864584.

53. Blumenfeld Z. How to preserve fertility in young women exposed to chemotherapy? The role of GnRH agonist cotreatment in addition to cryopreservation of embrya, oocytes, or ovaries. Oncologist 2007;12:1044-54.

54. Lambertini M, Horicks F, Del Mastro L, Partridge AH, Demeestere I. Ovarian protection with gonadotropin-releasing hormone agonists during chemotherapy in cancer patients: from biological evidence to clinical application. Cancer Treat Rev 2019;72:65-77.

55. Kitajima Y, Endo T, Nagasawa K, Manase K, Honnma H, Baba T, et al. Hyperstimulation and a gonadotropin-releasing hormone agonist modulate ovarian vascular permeability by altering expression of the tight junction protein claudin-5. Endocrinology 2006; 147:694-9.

56. Saitta A, Altavilla D, Cucinotta D, Morabito N, Frisina N, Corrado F, et al. Randomized, double-blind, placebo-controlled study on effects of raloxifene and hormone replacement therapy on plasma no concentrations, endothelin-1 levels, and endothelium-dependent vasodilation in postmenopausal women. Arterioscler Thromb Vasc Biol 2001;21:1512-9.

57. Grundker C, Emons G. Role of gonadotropin-releasing hormone (GnRH) in ovarian cancer. Reprod Biol Endocrinol 2003;1:65.

58. Harrison GS, Wierman ME, Nett TM, Glode LM. Gonadotropin-releasing hormone and its receptor in normal and malignant cells. Endocr Relat Cancer 2004;11:725-48.

59. Leung PC, Cheng CK, Zhu XM. Multi-factorial role of GnRH-I and GnRH-II in the human ovary. Mol Cell Endocrinol 2003;202:14553.

60. Imai A, Sugiyama M, Furui T, Tamaya T, Ohno T. Direct protection by a gonadotropin-releasing hormone analog from doxorubicin-induced granulosa cell damage. Gynecol Obstet Invest 2007; 63:102-6.

61. Morita Y, Perez Gl, Paris F, Miranda SR, Ehleiter D, Haimovitz-Fried- 
man A, et al. Oocyte apoptosis is suppressed by disruption of the acid sphingomyelinase gene or by sphingosine-1-phosphate therapy. Nat Med 2000;6:1109-14.

62. Li F, Turan V, Lierman S, Cuvelier C, de Sutter P, Oktay K. Sphingosine-1-phosphate prevents chemotherapy-induced human primordial follicle death. Hum Reprod 2014;29:107-13.

63. Zelinski MB, Murphy MK, Lawson MS, Jurisicova A, Pau KY, Toscano NP, et al. In vivo delivery of FTY720 prevents radiation-induced ovarian failure and infertility in adult female nonhuman primates. Fertil Steril 2011;95:1440-5.

64. Johnson J, Bagley J, Skaznik-Wikiel M, Lee HJ, Adams GB, Niikura Y, et al. Oocyte generation in adult mammalian ovaries by putative germ cells in bone marrow and peripheral blood. Cell 2005;122: 303-15.

65. Gargett CE. Review article: stem cells in human reproduction. Reprod Sci 2007; 14:405-24.

66. Blumenfeld Z. Fertility preservation using GnRH agonists: rationale, possible mechanisms, and explanation of controversy. Clin Med Insights Reprod Health 2019;13:1179558119870163.

67. Scaruffi P, Stigliani S, Cardinali B, Massarotti C, Lambertini M, Sozzi $\mathrm{F}$, et al. Gonadotropin releasing hormone agonists have an anti-apoptotic effect on cumulus cells. Int J Mol Sci 2019;20:6045.

68. Coccia PF, Pappo AS, Beaupin L, Borges VF, Borinstein SC, Chugh R, et al. Adolescent and young adult oncology, version 2.2018, NCCN Clinical Practice Guidelines in Oncology. J Natl Compr Canc Netw 2018;16:66-97.

69. Von Wolff M, Germeyer A, Liebenthron J, Korell M, Nawroth F. Practical recommendations for fertility preservation in women by the FertiPROTEKT network. Part II: fertility preservation techniques. Arch Gynecol Obstet 2018;297:257-67.

70. ISFP Practice Committee; Kim SS, Donnez J, Barri P, Pellicer A, Patrizio $\mathrm{P}$, et al. Recommendations for fertility preservation in patients with lymphoma, leukemia, and breast cancer. J Assist Reprod Genet 2012;29:465-8.

71. Klemp JR, Kim SS; ISFP Practice Committee. Fertility preservation in young women with breast cancer. J Assist Reprod Genet 2012; 29:469-72.

72. Giuseppe L, Attilio G, Edoardo DN, Loredana G, Cristina L, Vincenzo L. Ovarian function after cancer treatment in young women affected by Hodgkin disease (HD). Hematology 2007;12:141-7.

73. Gilani MM, Hasanzadeh M, Ghaemmaghami F, Ramazanzadeh F. Ovarian preservation with gonadotropin-releasing hormone analog during chemotherapy. Asia Pac J Clin Oncol 2007;3:79-83.

74. Badawy A, Elnashar A, El-Ashry M, Shahat M. Gonadotropin-releasing hormone agonists for prevention of chemotherapy-induced ovarian damage: prospective randomized study. Fertil Steril 2009;91:694-7.
75. Sverrisdottir A, Nystedt M, Johansson H, Fornander T. Adjuvant goserelin and ovarian preservation in chemotherapy treated patients with early breast cancer: results from a randomized trial. Breast Cancer Res Treat 2009;117:561-7.

76. Behringer K, Wildt L, Mueller H, Mattle V, Ganitis P, van den Hoonaard $B$, et al. No protection of the ovarian follicle pool with the use of $\mathrm{GnRH}$-analogues or oral contraceptives in young women treated with escalated BEACOPP for advanced-stage Hodgkin lymphoma: final results of a phase II trial from the German Hodgkin Study Group. Ann Oncol 2010;21:2052-60.

77. Gerber B, von Minckwitz G, Stehle H, Reimer T, Felberbaum R, Maass $\mathrm{N}$, et al. Effect of luteinizing hormone-releasing hormone agonist on ovarian function after modern adjuvant breast cancer chemotherapy: the GBG 37 ZORO study. J Clin Oncol 2011;29: 2334-41.

78. Munster PN, Moore AP, Ismail-Khan R, Cox CE, Lacevic M, GrossKing $\mathrm{M}$, et al. Randomized trial using gonadotropin-releasing hormone agonist triptorelin for the preservation of ovarian function during (neo)adjuvant chemotherapy for breast cancer. J Clin Oncol 2012;30:533-8.

79. Song G, Gao H, Yuan Z. Effect of leuprolide acetate on ovarian function after cyclophosphamide-doxorubicin-based chemotherapy in premenopausal patients with breast cancer: results from a phase II randomized trial. Med Oncol 2013;30:667.

80. Elgindy EA, El-Haieg DO, Khorshid OM, Ismail El, Abdelgawad M, Sallam HN, et al. Gonadatrophin suppression to prevent chemotherapy-induced ovarian damage: a randomized controlled trial. Obstet Gynecol 2013;121:78-86.

81. Karimi-Zarchi M, Forat-Yazdi M, Vafaeenasab MR, Nakhaie-Moghadam M, Miratashi-Yazdi A, Teimoori S, et al. Evaluation of the effect of GnRH agonist on menstrual reverse in breast cancer cases treated with cyclophosphamide. Eur J Gynaecol Oncol 2014;35: 59-61.

82. Lambertini M, Boni L, Michelotti A, Gamucci T, Scotto T, Gori S, et al. Ovarian suppression with triptorelin during adjuvant breast cancer chemotherapy and long-term ovarian function, pregnancies, and disease-free survival: a randomized clinical trial. JAMA 2015;314:2632-40.

83. Moore HC, Unger JM, Phillips KA, Boyle F, Hitre E, Porter D, et al. Goserelin for ovarian protection during breast-cancer adjuvant chemotherapy. N Engl J Med 2015;372:923-32.

84. Demeestere I, Brice P, Peccatori FA, Kentos A, Dupuis J, Zachee P, et al. No evidence for the benefit of gonadotropin-releasing hormone agonist in preserving ovarian function and fertility in lymphoma survivors treated with chemotherapy: final long-term report of a prospective randomized trial. J Clin Oncol 2016;34: 2568-74. 
85. Leonard RC, Adamson DJ, Bertelli G, Mansi J, Yellowlees A, Dunlop J, et al. GnRH agonist for protection against ovarian toxicity during chemotherapy for early breast cancer: the Anglo Celtic Group OPTION trial. Ann Oncol 2017;28:1811-6.

86. Zhang Y, Ji Y, Li J, Lei L, Wu S, Zuo W, et al. Sequential versus simultaneous use of chemotherapy and gonadotropin-releasing hormone agonist (GnRHa) among estrogen receptor (ER)-positive premenopausal breast cancer patients: effects on ovarian function, disease-free survival, and overall survival. Breast Cancer Res Treat 2018;168:679-86.

87. Zhong Y, Lin Y, Cheng X, Huang X, Zhou Y, Mao F, et al. GnRHa for ovarian protection and the association between amh and ovarian function during adjuvant chemotherapy for breast cancer. J Cancer 2019;10:4278-85.

88. Hickman LC, Llarena NC, Valentine LN, Liu X, Falcone T. Preservation of gonadal function in women undergoing chemotherapy: a systematic review and meta-analysis of the potential role for gonadotropin-releasing hormone agonists. J Assist Reprod Genet 2018;35:571-81.

89. Sofiyeva N, Siepmann T, Barlinn K, Seli E, Ata B. Gonadotropin-releasing hormone analogs for gonadal protection during gonadotoxic chemotherapy: a systematic review and meta-analysis. Reprod Sci 2019;26:939-53.

90. Bai F, Lu Y, Wu K, Chen Q, Ding L, Ge M, et al. Protecting effects of gonadotropin-releasing hormone agonist on chemotherapy-induced ovarian damage in premenopausal breast cancer patients: a systematic review and meta-analysis. Breast Care (Basel) 2017; 12:48-52.

91. Senra JC, Roque M, Talim MC, Reis FM, Tavares RL. Gonadotropin-releasing hormone agonists for ovarian protection during cancer chemotherapy: systematic review and meta-analysis. UItrasound Obstet Gynecol 2018;51:77-86.

92. Elgindy E, Sibai H, Abdelghani A, Mostafa M. Protecting ovaries during chemotherapy through gonad suppression: a systematic review and meta-analysis. Obstet Gynecol 2015;126:187-95.

93. Lambertini M, Ceppi M, Poggio F, Peccatori FA, Azim HA Jr, Ugolini $D$, et al. Ovarian suppression using luteinizing hormone-releasing hormone agonists during chemotherapy to preserve ovarian function and fertility of breast cancer patients: a meta-analysis of randomized studies. Ann Oncol 2015;26:2408-19.

94. Munhoz RR, Pereira AA, Sasse AD, Hoff PM, Traina TA, Hudis CA, et al. Gonadotropin-releasing hormone agonists for ovarian function preservation in premenopausal women undergoing chemotherapy for early-stage breast cancer: a systematic review and meta-analysis. JAMA Oncol 2016;2:65-73.

95. Lambertini M, Moore HC, Leonard RC, Loibl S, Munster P, Bruzzone $\mathrm{M}$, et al. Gonadotropin-releasing hormone agonists during chemotherapy for preservation of ovarian function and fertility in premenopausal patients with early breast cancer: a systematic review and meta-analysis of individual patient-level data. J Clin Oncol 2018;36:1981-90.

96. Chen H, Xiao L, Li J, Cui L, Huang W. Adjuvant gonadotropin-releasing hormone analogues for the prevention of chemotherapy-induced premature ovarian failure in premenopausal women. Cochrane Database Syst Rev 2019;3:CD008018.

97. Oktay K, Turan V. Failure of ovarian suppression with gonadotropin-releasing hormone analogs to preserve fertility: an assessment based on the quality of evidence. JAMA Oncol 2016;2:745.

98. Silva C, Caramelo O, Almeida-Santos T, Ribeiro Rama AC. Factors associated with ovarian function recovery after chemotherapy for breast cancer: a systematic review and meta-analysis. Hum Reprod 2016;31:2737-49.

99. Ortmann O, Weiss JM, Diedrich K. Gonadotrophin-releasing hormone (GnRH) and GnRH agonists: mechanisms of action. Reprod Biomed Online 2002;5 Suppl 1:1-7.

100. Meirow D, Biederman H, Anderson RA, Wallace WH. Toxicity of chemotherapy and radiation on female reproduction. Clin Obstet Gynecol 2010;53:727-39.

101. Mantel N, Haenszel W. Statistical aspects of the analysis of data from retrospective studies of disease. J Natl Cancer Inst 1959;22: 719-48.

102. Blumenfeld Z. ZORO study: discrepancy between the conclusion and the results. J Clin Oncol 2011;29:3340.

103. Turner NH, Partridge A, Sanna G, Di Leo A, Biganzoli L. Utility of gonadotropin-releasing hormone agonists for fertility preservation in young breast cancer patients: the benefit remains uncertain. Ann Oncol 2013;24:2224-35.

104. Bedoschi G, Turan V, Oktay K. Utility of GnRH-agonists for fertility preservation in women with operable breast cancer: is it protective? Curr Breast Cancer Rep 2013;5:302-8.

105. Goldenberg GJ, Froese EK. Antagonism of the cytocidal activity and uptake of melphalan by tamoxifen in human breast cancer cells in vitro. Biochem Pharmacol 1985;34:763-70.

106. Woods KE, Randolph JK, Gewirtz DA. Antagonism between tamoxifen and doxorubicin in the MCF-7 human breast tumor cell line. Biochem Pharmacol 1994;47:1449-52.

107. Albain KS, Barlow WE, Ravdin PM, Farrar WB, Burton GV, Ketchel SJ, et al. Adjuvant chemotherapy and timing of tamoxifen in postmenopausal patients with endocrine-responsive, node-positive breast cancer: a phase 3, open-label, randomised controlled trial. Lancet 2009;374:2055-63.

108. International Breast Cancer Study Group. Late effects of adjuvant oophorectomy and chemotherapy upon premenopausal breast 
cancer patients. Ann Oncol 1990;1:30-5.

109. Rivkin SE, Green S, O'Sullivan J, Cruz AB, Abeloff MD, Jewell WR, et al. Adjuvant CMFVP versus adjuvant CMFVP plus ovariectomy for premenopausal, node-positive, and estrogen receptor-positive breast cancer patients: a Southwest Oncology Group study. J Clin Oncol 1996;14:46-51.

110. Arriagada R, Le MG, Spielmann M, Mauriac L, Bonneterre J, Namer $\mathrm{M}$, et al. Randomized trial of adjuvant ovarian suppression in 926 premenopausal patients with early breast cancer treated with adjuvant chemotherapy. Ann Oncol 2005;16:389-96.

111. Pagani O, Regan MM, Walley BA, Fleming GF, Colleoni M, Lang I, et al. Adjuvant exemestane with ovarian suppression in premenopausal breast cancer. N Engl J Med 2014;371:107-18.

112. Gradishar WJ, Anderson BO, Balassanian R, Blair SL, Burstein HJ, Cyr A, et al. Invasive breast cancer version 1.2016, NCCN Clinical Practice Guidelines in Oncology. J Natl Compr Canc Netw 2016; 14:324-54.

113. Coates AS, Winer EP, Goldhirsch A, Gelber RD, Gnant M, Piccart-Gebhart M, et al. Tailoring therapies: improving the management of early breast cancer: St Gallen International Expert Consensus on the Primary Therapy of Early Breast Cancer 2015. Ann Oncol 2015;26:1533-46.

114. Paluch-Shimon S, Pagani O, Partridge AH, Bar-Meir E, Fallowfield L, Fenlon D, et al. Second international consensus guidelines for breast cancer in young women (BCY2). Breast 2016;26:87-99.

115. Dunlop CE, Anderson RA. Uses of anti-Mullerian hormone (AMH) measurement before and after cancer treatment in women. Maturitas 2015;80:245-50.

116. Lunsford AJ, Whelan K, McCormick K, McLaren JF. Antimullerian hormone as a measure of reproductive function in female child- hood cancer survivors. Fertil Steril 2014;101:227-31.

117. Miyoshi Y, Yasuda K, Miyamura T, Miyashita E, Hashii Y, Ozono K. Anti-Mullerian hormone is a useful marker of gonadotoxicity in girls treated for cancer: a prospective study. Horm Res Paediatr 2015;84:479.

118. Anderson RA, Wallace WH. Antimullerian hormone, the assessment of the ovarian reserve, and the reproductive outcome of the young patient with cancer. Fertil Steril 2013;99:1469-75.

119. Peigne M, Decanter C. Serum AMH level as a marker of acute and long-term effects of chemotherapy on the ovarian follicular content: a systematic review. Reprod Biol Endocrinol 2014;12:26.

120. Freour T, Barriere P, Masson D. Anti-mullerian hormone levels and evolution in women of reproductive age with breast cancer treated with chemotherapy. Eur J Cancer 2017;74:1-8.

121. Steiner AZ, Pritchard D, Stanczyk FZ, Kesner JS, Meadows JW, Herring $\mathrm{AH}$, et al. Association between biomarkers of ovarian reserve and infertility among older women of reproductive age. JAMA 2017;318:1367-76.

122. Hamy AS, Porcher R, Eskenazi S, Cuvier C, Giacchetti S, Coussy F, et al. Anti-Mullerian hormone in breast cancer patients treated with chemotherapy: a retrospective evaluation of subsequent pregnancies. Reprod Biomed Online 2016;32:299-307.

123. Janse F, Donnez J, Anckaert E, de Jong FH, Fauser BC, Dolmans MM. Limited value of ovarian function markers following orthotopic transplantation of ovarian tissue after gonadotoxic treatment. J Clin Endocrinol Metab 2011;96:1136-44.

124. Lambertini M, Del Mastro L, Pescio MC, Andersen CY, Azim HA Jr, Peccatori FA, et al. Cancer and fertility preservation: international recommendations from an expert meeting. BMC Med 2016;14:1. 